\title{
Control Measures and Health Effects of Air Pollution: A Survey among Public Transportation Commuters in Malaysia
}

\author{
Li Ping Wong ${ }^{1, *}(\mathbb{D})$, Haridah Alias ${ }^{1}$, Nasrin Aghamohammadi ${ }^{2}$, Azadeh Ghadimi ${ }^{3}$ and \\ Nik Meriam Nik Sulaiman ${ }^{4}$ \\ 1 Julius Centre University of Malaya (JCUM), Department of Social and Preventive Medicine, \\ Faculty of Medicine, University of Malaya, 50603 Kuala Lumpur, Malaysia; haridahalias@gmail.com \\ 2 Centre for Occupational and Environmental Health, Department of Social and Preventive Medicine, \\ Faculty of Medicine, University of Malaya, 50603 Kuala Lumpur, Malaysia; nasrin@ummc.edu.my \\ 3 School of Engineering, Taylors University Lake Side Campus, 47500 Selangor, Malaysia; \\ azadeh.ghadimi@taylors.edu.my \\ 4 Department of Chemical Engineering, Faculty of Engineering, University of Malaya, 50603 Kuala Lumpur, \\ Malaysia; meriam@um.edu.my \\ * Correspondence: wonglp@ummc.edu.my; Tel.: +60-3-7967-5778
}

Received: 18 July 2017; Accepted: 7 September 2017; Published: 11 September 2017

\begin{abstract}
This research aimed to investigate the control measures used by public transport commuters and their health (physical and psychological) effects due to exposure to air pollution during their daily commute and during haze days. From June to October 2016, 800 public transport commuters in urban cities in the heart of Selangor, Malaysia were interviewed. Of these, $25.4 \%$ reported sometimes/often wearing surgical masks during their daily commute, while $92.1 \%$ reported such use during haze days. The total control measure score against air pollutants during the daily commute was low; on a control measure scale of $0-18$, the median rating during the daily commute was 8 (interquartile range (IQR) 6-10). During haze days, control measures improved slightly (median 14, IQR 12-16). Evidence of adverse health effects was present. During the daily commute under normal conditions, the three highest adverse health experiences were fatigue and weakness $(35.5 \%)$, coughing $(23.6 \%)$, and dizziness $(18.2 \%)$. During haze days, the three highest adverse health experiences were headache $(85 \%)$, coughing $(84.8 \%)$, and breathing difficulties $(84.5 \%)$. On a possible total adverse health (physical and psychological) experience scale of $0-22$, the median rating during the daily commute was 1 (IQR 0-3). The median rating during haze days was intensified (median 11, IQR 9-13). Public transportation commuters should be encouraged to enhance various control measures against particulate air pollutants during their daily commute, particularly during haze days, to minimize the adverse health risks associated with air pollutants.
\end{abstract}

Keywords: control measures; health effects; air pollution; commuters

\section{Introduction}

In urban areas, commuting by public transportation can bring convenience, cost-savings, and less stress for commuters, compared to those who drive to work. Use of public transport may also prevent roadway congestion, result in shorter commute times, and increase productivity. However, public transport commuters are particularly affected by high concentrations of air pollutants, both originated from vehicular traffic or those caused by other urban, industrial or environmental factors, during their transit. Road vehicle emissions are one of the most important sources of human exposure to air pollution. Air pollution concentrations on roads are relatively high and commuters face 
unavoidable outdoor exposure during commuting from home to metropolitan rail transit stations and waiting for public transportation. Emissions from road traffic result in a complex mixture of harmful air pollutants, which are known to have adverse effects on health [1]. In particular, studies have shown that exposure to air pollution in traffic is related to short-term cardiovascular and respiratory health effects [2-6]. Much evidence has also been found showing the prevalence of respiratory disease symptoms in individuals who live close to high-traffic roads $[7,8]$.

In recent years, atmospheric haze in Southeast Asia (mainly due to pollution from forest and peat fires in Indonesia) has become a main concern in Malaysia. In urban areas, haze worsens the existing burden of traffic-related air pollution. The health impact of such haze has been shown to produce a $30 \%$ increase in outpatient attendance during haze-related conditions [9]. An increase in $\mathrm{PM}_{10}$ (particulate matter 10 micrometers or less in diameter) levels from $50 \mu \mathrm{g} / \mathrm{m}^{3}$ to $150 \mu \mathrm{g} / \mathrm{m}^{3}$ is significantly associated with increases of $12 \%$ for upper respiratory tract illness, $19 \%$ for asthma, and $26 \%$ for rhinitis [9]. Air pollution in general, whether from traffic-related, industrial, or haze-caused pollutants, is considered a major threat to human health at the population level because of its link to increased mortality [10]. While effective policies to reduce air pollution at the source are clearly more effective, various reports support the effectiveness of personal actions to reduce exposure and health risks. Using highly efficient face masks evidently reduces personal exposure to air pollution and improves a range of cardiovascular health measures in patients with coronary heart disease [11]. Masks labeled as N95 filter at least 95\% of airborne aerosol with a mass median aerodynamic particle diameter of about $0.3 \mu \mathrm{m}$. The use of $\mathrm{N} 95$ masks has been recommended during haze days [12].

In addition to outdoor care, preventive medications or supplements have also been suggested [13]. Patients with chronic airway diseases are encouraged to take medications that can increase their immunologic function. Multivitamin use is also encouraged to protect against the impact of air pollution, as is the use of supplements such as vitamin C, which is an antioxidant that can reduce the oxidative stress reaction and build the immune system against air pollutant-related health problems [13]. Drinking additional water has been recommended to reduce throat irritation and to help the kidneys flush out any absorbed toxins [12]. Fruits and vegetables high in antioxidants are also highly recommended to neutralize free radical damage caused by air contamination.

In Malaysia, there is relatively scarce evidence on epidemiological studies on the health effects from traffic-related air pollution. A recent study on urban ambient air quality and health effects in Kuala Lumpur, the capital of Malaysia, revealed a moderate level of air quality [14]. Illnesses related to air pollution were significantly associated with ambient air quality and also proportionate with the duration of time spent in areas with air pollution [14]. Further, in recent years, Malaysia also has been greatly impacted by the frequent occurrence of atmospheric haze in Southeast Asia. Haze has now become a regular environmental condition. Consequently, travelling by public transport exposes commuters to greater levels of air pollutants, both from traffic-related and haze-caused conditions. The extent to which exposure to air pollutants during daily commuting by public transport may have contributed to adverse health among commuters in Malaysia has never been investigated. Further, no studies have been conducted specifically among Malaysian commuters on control measures taken to reduce impact of air pollution. Therefore, the aims of this study were to investigate the control measures used by commuters and their health effects due to exposure to air pollution during their daily commute via public transport. Control measures and adverse health effects during haze days were also investigated.

\section{Materials and Methods}

\subsection{Study Participants and Settings}

Data collection was carried out from June to October 2016. Face-to-face interviews were carried out by interviewers during weekdays and normal office hours. A convenience sampling method was used, whereby random commuters were approached at all the Light Rail Transit train stations along 
the Kelana Jaya and Ampang lines in the state of Selangor, Malaysia. Before the start of the interview, the interviewers gave a standardized introduction, informed consent was obtained from the study participants, and participants were assured of the confidentiality of their information. The study was approved by the University of Malaya Medical Ethics Committee (MECID NO: 201698-4239).

\subsection{Study Questionnaire}

An interviewer-assisted questionnaire was developed by a panel of experts from the Department of Social Preventive Medicine, Faculty of Medicine, University of Malaya. The survey questionnaire was available in two languages: Bahasa Malaysia (Malaysian national language) and English. The questions were carefully read aloud to participants by the interviewers. The questionnaire consisted of three sections. In the first section, demographic data were collected. Additionally, other questions were asked about health risks: duration spent commuting via public transport, living near a highway, smoking status, and the presence of chronic diseases.

In the second section, a total of 12 questions probed participants' control measures used to reduce the effect of air pollution during their daily commute (six items) and during haze days (six items). The response options included never, rarely, sometimes, and often, and scored as 0, 1, 2, and 3, respectively. Thus, total possible scores ranged from 0 to 18 , with a higher score implying a higher level of control measures. The third section assessed participants' self-reporting of adverse health experiences (both physical health, 15 items, and psychological health, seven items) from exposure to air pollution during their daily commute days and during haze days, with each requiring a "yes" or "no" response. Each "yes" response was rated as 1 and each "no" response was rated as 0 . Therefore, the total possible score ranged from 0 to 22 , with a higher score implying higher levels of adverse health.

\subsection{Data Analyses}

Data were statistically analyzed with SPSS statistics version 19.0 (SPSS Inc., Chicago, IL, USA). Descriptive analysis was performed to determine the frequency distribution of demographics, control measures, and adverse health experiences. The total scores of control measures and adverse health experiences were subjected to normality tests to explore the score distributions. As both total scores were not normally distributed, K-means clustering was performed to cluster the scores with similar patterns into two clusters [15]. The Chi-square test was used to examine the association between each of the independent variables and the clusters for both total scores of control measures and adverse health experiences. Multivariate logistic analysis was subsequently carried out if there were two or more significant associations $(p<0.05)$ in the univariate analysis. All significant variables in the univariate analysis were entered into multivariate logistic regression analysis using a simultaneous forced entry model (enter method). Odds ratios (OR), 95\% confidence intervals (95\% CI), and $p$-values were calculated for each independent variable. The model fit was assessed using the Hosmer-Lemeshow goodness of fit [16].

\section{Results}

A total of 800 respondents completed the survey (response rate approximately $45 \%$ ). As shown in Table 1, the majority of the respondents were aged 30 years and below $(56.5 \%)$. By occupational group, the majority of the respondents were professional or managerial (52.4\%), followed by skilled or non-skilled workers $(40.6 \%)$. Most of the participants had an average monthly income of MYR5000 $(81.4 \%)$. The ethnic and gender distribution of the study participants closely matched that of the general Malaysian population. Slightly over half of the study respondents spent less than one hour commuting by public transport daily $(59.0 \%)$. A total of $36.5 \%$ reported living near a highway, $6.4 \%$ had chronic diseases, and $38.6 \%$ were smokers. 
Table 1. Demographic characteristics and other exposure risks, $n=800$.

\begin{tabular}{|c|c|}
\hline Details & Frequency, $n(\%)$ \\
\hline \multicolumn{2}{|l|}{ (A) Socio-demographic data } \\
\hline \multicolumn{2}{|l|}{ Age group (years old) } \\
\hline 30 and below & $452(56.5)$ \\
\hline $31-40$ & $265(33.1)$ \\
\hline$>40$ & $83(10.4)$ \\
\hline \multicolumn{2}{|l|}{ Gender } \\
\hline Male & $424(53.0)$ \\
\hline Female & $376(47.0)$ \\
\hline \multicolumn{2}{|l|}{ Marital status } \\
\hline Single & $414(51.8)$ \\
\hline Married & $386(48.3)$ \\
\hline \multicolumn{2}{|l|}{ Ethnicity } \\
\hline Malay & $388(48.5)$ \\
\hline Chinese & $271(33.9)$ \\
\hline Indian & $138(17.3)$ \\
\hline Others & $3(0.4)$ \\
\hline \multicolumn{2}{|l|}{ Education } \\
\hline Secondary level and below & $146(18.2)$ \\
\hline Tertiary level & $654(81.8)$ \\
\hline \multicolumn{2}{|l|}{ Occupation } \\
\hline Professional/managerial & $419(52.4)$ \\
\hline Skilled/non-skilled worker & $314(40.6)$ \\
\hline Student & $54(6.8)$ \\
\hline Housewife & $2(0.2)$ \\
\hline \multicolumn{2}{|l|}{ Monthly income (MYR) } \\
\hline 5000 and below & $651(81.4)$ \\
\hline$>5000$ & 149 (18.6) \\
\hline \multicolumn{2}{|l|}{ (B) Other exposure risks } \\
\hline \multicolumn{2}{|l|}{ Chronic diseases } \\
\hline Yes & $51(6.4)$ \\
\hline No & 749 (93.6) \\
\hline \multicolumn{2}{|l|}{ Smoking status } \\
\hline Yes & 309 (38.6) \\
\hline No & $491(61.4)$ \\
\hline \multicolumn{2}{|l|}{ Living near highway } \\
\hline Yes & $292(36.5)$ \\
\hline No & $508(63.5)$ \\
\hline \multicolumn{2}{|c|}{ Duration spent commuting by public transport (hours) } \\
\hline $1 \mathrm{~h}$ and below & $472(59.0)$ \\
\hline$>1 \mathrm{~h}$ & $328(41.0)$ \\
\hline
\end{tabular}

Table 2 shows the proportion of control measures used by study participants during daily commutes on both normal and haze days. During their daily commute, the majority reported never/rarely using the control measures queried. Relatively higher proportions reported a frequency of sometimes/often, rather than never/rarely, in regard to drinking more water and increasing their consumption of fruits and vegetables. The majority $(78.1 \%)$ reported sometimes/often drinking more water, and $51.1 \%$ reported sometimes/often increasing their consumption of fresh fruits or vegetables. In regard to using a surgical mask, only a small proportion (25.4\%) reported a usage frequency of sometimes/often during their daily commute. Overall, the proportions of control measures taken by participants were higher during haze days than regular daily commute days. For control measures, on a rating scale of $0-18$, the median rating for the daily commute was 8 (interquartile range (IQR) 6-10). The median rating during haze days was slightly higher (median 14, IQR 12-16). Of all the control measures, the use of a surgical mask recorded the highest increase during haze days. 
Table 2. Proportion of control measures during daily commuting compared with during haze days $(n=800)$.

\begin{tabular}{|c|c|c|c|c|}
\hline & \multicolumn{2}{|c|}{ During Daily Commute } & \multicolumn{2}{|c|}{ During Haze Days } \\
\hline & $\begin{array}{c}\text { Never/Rarely } \\
n(\%)\end{array}$ & $\begin{array}{l}\text { Sometimes/Often } \\
n(\%)\end{array}$ & $\begin{array}{c}\text { Never/Rarely } \\
n(\%)\end{array}$ & $\begin{array}{c}\text { Sometimes/Often } \\
n(\%)\end{array}$ \\
\hline Use normal surgical mask & $597(74.6)$ & $203(25.4)$ & $63(7.9)$ & $737(92.1)$ \\
\hline Use dust masks N95 during severe haze day & $703(87.9)$ & $97(12.1)$ & $272(34.0)$ & $528(66.0)$ \\
\hline Drink more water & $175(21.9)$ & $625(78.1)$ & $7(0.9)$ & $793(99.1)$ \\
\hline Increase the intake of fresh fruits or vegetables & $327(40.9)$ & $473(59.1)$ & $65(8.1)$ & $735(91.9)$ \\
\hline $\begin{array}{c}\text { Take food supplements } \\
\text { (vitamins, nutrients, herbal products) }\end{array}$ & $481(60.1)$ & $319(39.9)$ & $254(31.8)$ & $546(68.2)$ \\
\hline $\begin{array}{l}\text { As much as possible commute using } \\
\text { alternative transportation } \\
\text { (e.g., friends car) to avoid exposure }\end{array}$ & $450(56.3)$ & $350(43.8)$ & $316(39.5)$ & $484(60.5)$ \\
\hline
\end{tabular}

K-means clustering segregated the total control measures scores into two clusters: normal days (Cluster I) and haze days (Cluster II). For control measures during normal days, the total control measures for Cluster I ranged 0-8, whereas those for Cluster II ranged 9-18. As shown in Table 3, there were significant associations between total control measures of both clusters with regard to demographic characteristics. A higher proportion of non-smoking participants than smoking participants reported total control measures scoring 9-18 (Cluster II). For control measures during haze days, a significantly higher proportion of married participants (83.9\%) than never married $(77.8 \%)$ reported total control measures scoring 12-18 (Cluster II). There was a near significant difference between the total control measures of both clusters regarding age: a higher proportion of participants aged $31-40(85.3 \%)$ and over $40(81.9 \%)$ reported total control measures scoring $12-18(p=0.05)$. There was also a near significant difference between total control measures of both clusters regarding living near a highway. A lower proportion of participants who live near a highway (77.1\%), compared to those not living near a highway (82.9\%), reported total control measures scoring 12-18 (Cluster II).

Figure 1 shows the proportion of adverse physical health experiences during normal commuting days and haze days. During the daily commute, the three highest adverse health experiences were fatigue and weakness $(35.5 \%)$, coughing $(23.6 \%)$, and dizziness $(18.2 \%)$. During haze days, the three highest adverse health experiences were headache (85\%), coughing $(84.8 \%)$, and breathing difficulties (84.5\%). Overall, the proportions of adverse physical health experiences were higher than for psychological health experiences during both normal commuting days and haze days. Among all psychological health experiences queried, stress was the experience that was reported highest during both normal commuting days (13.0\%) and haze days (50.6\%) (Figure 2). Overall, the proportions of both adverse physical and psychological health experiences were higher during haze days compared with normal commuting days. For adverse health experiences, using a scale of 0-22 for both physical and psychological health, the median rating during normal commuting days was 1 (IQR 0-3), and the median rating during haze days was 11 (IQR 9-13).

Likewise, K-means clustering was performed to cluster the total adverse health experience scores (total of both physical and psychological health) with similar patterns into two clusters for both normal commuting days and haze days. For adverse health experiences during normal commuting days, the total adverse health experiences in Cluster I ranged 0-4, whereas those for Cluster II ranged 5-22. As shown in Table 4, there were no significant differences between total adverse health experiences of both clusters with regard to demographic characteristics and other risks during daily commuting. For adverse health experiences during haze days, a significantly higher proportion of participants aged $31-40(50.2 \%)$ reported a total adverse health experience score of 12-22 (Cluster II), compared to those aged 30 and below (45.1\%) and those aged 40 and above (34.9\%). In multivariate analysis, participants aged 31-40 reported significantly higher likelihood of higher total adverse health experiences than those aged 40 and above (OR $=1.852 ; 95 \%$ CI 1.107-3.099). There was also a significant association between 
the clusters of total control measure score and the clusters of total adverse health experiences during haze days in the univariate analysis, and the association remains significant in the multivariate logistic regression. Participants with higher total control measures (Cluster II) were more likely to report having higher total adverse health experiences (score of 5-22) ( $\mathrm{OR}=1.907 ; 95 \%$ CI 1.315-2.765). Likewise, there was also a near significant difference $(p=0.055)$ between total adverse health experiences of both clusters and living near a highway. A higher proportion of participants who live near a highway (50.3\%), compared to those not living near a highway (43.1\%), reported a total adverse health experience score of 5-22 (Cluster II).

Table 3. Association between socio demographic, exposure risks and total control measure score during daily commute and haze days $(n=800)$.

\begin{tabular}{|c|c|c|c|c|c|c|c|}
\hline & \multicolumn{7}{|c|}{ Total Control Measure Score } \\
\hline & \multirow[b]{2}{*}{ Total } & \multicolumn{3}{|c|}{ During Daily Commute } & \multicolumn{3}{|c|}{ During Haze Days } \\
\hline & & $\begin{array}{c}\text { Cluster I } \\
0-8 \\
(n=440)\end{array}$ & $\begin{array}{c}\text { Cluster II } \\
9-18 \\
(n=360)\end{array}$ & $p$-Value & $\begin{array}{c}\text { Cluster I } \\
0-11 \\
(n=154)\end{array}$ & $\begin{array}{c}\text { Cluster II } \\
12-18 \\
(n=646)\end{array}$ & $p$-Value \\
\hline \multicolumn{8}{|c|}{ (A) SOCIO-DEMOGRAPHIC DATA } \\
\hline \multicolumn{8}{|c|}{ Age group (years old) } \\
\hline 30 and below & $452(56.5)$ & $244(54.0)$ & $208(46.0)$ & & $100(22.1)$ & $352(77.9)$ & \\
\hline $31-40$ & $265(33.1)$ & $147(55.5)$ & $118(44.5)$ & 0.684 & $39(14.7)$ & $226(85.3)$ & 0.050 \\
\hline$>40$ & $83(10.4)$ & $49(59.0)$ & $34(41.0)$ & & $15(18.1)$ & $68(81.9)$ & \\
\hline \multicolumn{8}{|l|}{ Gender } \\
\hline Male & $424(53.0)$ & $233(55.0)$ & $191(45.0)$ & 1.000 & $82(19.3)$ & $342(80.7)$ & 1.000 \\
\hline Female & $376(47.0)$ & $207(55.1)$ & $169(44.9)$ & & $72(19.1)$ & $304(80.9)$ & \\
\hline \multicolumn{8}{|l|}{ Marital status } \\
\hline Single & $414(51.8)$ & $235(56.8)$ & $179(43.2)$ & 0.320 & $92(22.2)$ & $322(77.8)$ & 0.031 \\
\hline Married & $386(48.3)$ & $205(53.1)$ & $181(46.9)$ & & $62(16.1)$ & $324(83.9)$ & \\
\hline \multicolumn{8}{|l|}{ Ethnicity } \\
\hline Malay & $388(48.5)$ & $212(54.6)$ & $176(45.4)$ & & $81(20.9)$ & $307(79.1)$ & \\
\hline Chinese & $271(33.9)$ & $143(52.8)$ & $128(47.2)$ & 0.383 & $52(19.2)$ & $219(80.8)$ & 0.053 \\
\hline Indian & $138(17.3)$ & $84(60.9)$ & $54(39.1)$ & & $19(13.8)$ & $119(86.2)$ & \\
\hline Others & $3(0.4)$ & $1(33.3)$ & $2(66.7)$ & & $2(66.7)$ & $1(33.3)$ & \\
\hline \multicolumn{8}{|l|}{ Highest education level } \\
\hline Secondary level and below & $146(18.2)$ & $88(60.3)$ & $58(39.7)$ & 0.168 & $28(19.2)$ & $118(80.8)$ & 1.000 \\
\hline Tertiary level & $654(81.8)$ & $352(53.8)$ & $302(46.2)$ & & $126(19.3)$ & $528(80.7)$ & \\
\hline \multicolumn{8}{|l|}{ Occupation } \\
\hline Professional/managerial & $419(52.4)$ & $224(53.5)$ & $195(46.5)$ & & $87(20.8)$ & $332(79.2)$ & \\
\hline Skilled/non-skilled worker & $314(40.6)$ & $184(56.6)$ & $141(43.4)$ & 0.310 & $55(16.9)$ & $270(83.1)$ & 0.469 \\
\hline Student & $54(6.8)$ & $32(59.3)$ & $22(40.7)$ & & $12(22.2)$ & $42(77.8)$ & \\
\hline Housewife & $2(0.2)$ & $0(100.0)$ & $2(100.0)$ & & $0(0.0)$ & $2(100.0)$ & \\
\hline \multicolumn{8}{|l|}{ Monthly income (MYR) } \\
\hline 5000 and below & $651(81.4)$ & $359(55.1)$ & $292(44.9)$ & & $125(19.2)$ & $526(80.8)$ & \\
\hline$>5000$ & $149(18.6)$ & $81(54.4)$ & $68(45.6)$ & 0.927 & $29(19.5)$ & $120(80.5)$ & 0.909 \\
\hline \multicolumn{8}{|l|}{ (B) OTHER RISKS } \\
\hline \multicolumn{8}{|l|}{ Chronic diseases } \\
\hline Yes & $51(6.4)$ & $25(49.0)$ & $26(51.0)$ & 0.386 & $10(19.6)$ & $41(80.4)$ & 1.000 \\
\hline No & $749(93.6)$ & $415(55.4)$ & $334(44.6)$ & & $144(19.2)$ & $605(80.8)$ & \\
\hline \multicolumn{8}{|l|}{ Smoking status } \\
\hline Yes & $309(38.6)$ & $184(59.5)$ & $125(40.5)$ & 0.041 & $56(18.1)$ & $253(81.9)$ & 0.581 \\
\hline No & $491(61.4)$ & $256(52.1)$ & $235(47.9)$ & & $98(20.0)$ & $393(80.0)$ & \\
\hline \multicolumn{8}{|l|}{ Living near highway } \\
\hline Yes & $292(36.5)$ & $159(54.5)$ & $133(45.5)$ & 0.825 & $67(22.9)$ & $225(77.1)$ & 0.050 \\
\hline No & $508(63.5)$ & $281(55.3)$ & $227(44.7)$ & & $87(17.1)$ & $421(82.9)$ & \\
\hline \multicolumn{8}{|l|}{$\begin{array}{l}\text { Duration spent commuting } \\
\text { by public transport (hours) }\end{array}$} \\
\hline $1 \mathrm{~h}$ and below & $472(59.0)$ & $258(54.7)$ & $214(45.3)$ & 0.829 & $98(20.8)$ & $374(79.2)$ & 0.203 \\
\hline$>1 \mathrm{~h}$ & $328(41.0)$ & $182(55.5)$ & $146(44.5)$ & & $56(17.1)$ & $272(82.9)$ & \\
\hline
\end{tabular}




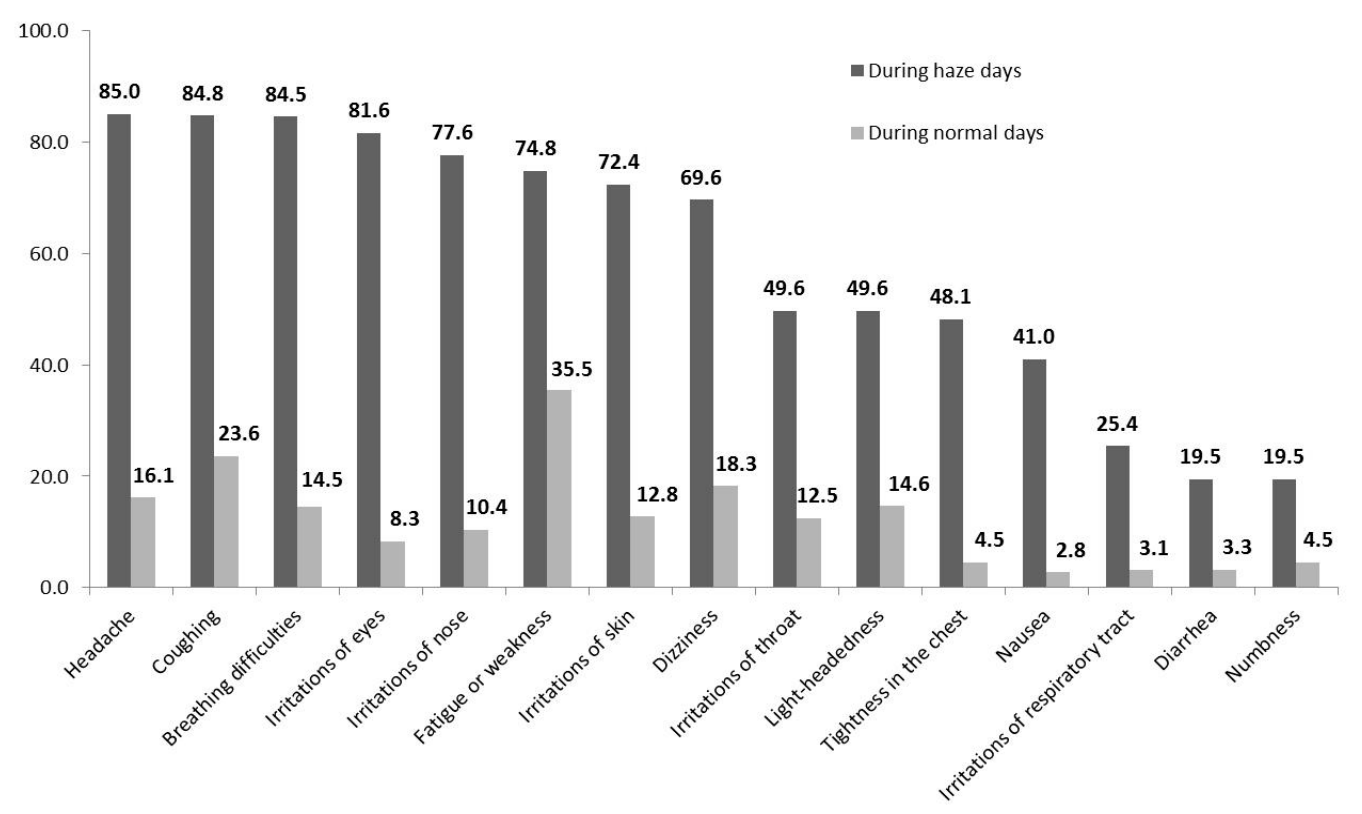

Figure 1. Proportion (\%) of adverse physical health experienced (\%) during daily commute and haze days $(n=800)$.

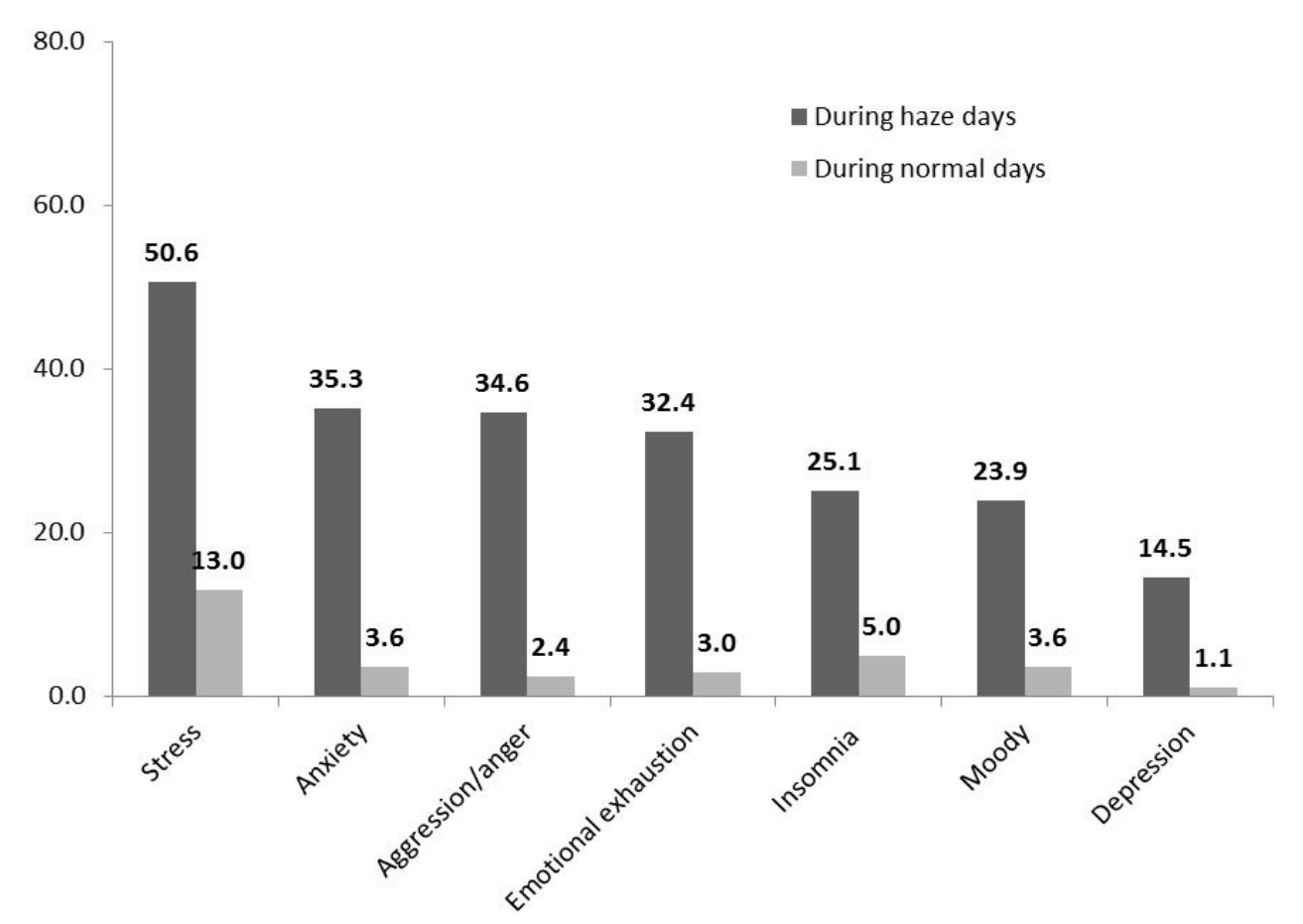

Figure 2. Proportion (\%) of adverse psychological health experienced during daily commute and haze days $(n=800)$. 
Table 4. Factors associated to total physical and psychological health experience score during daily commute and haze days $(n=800)$.

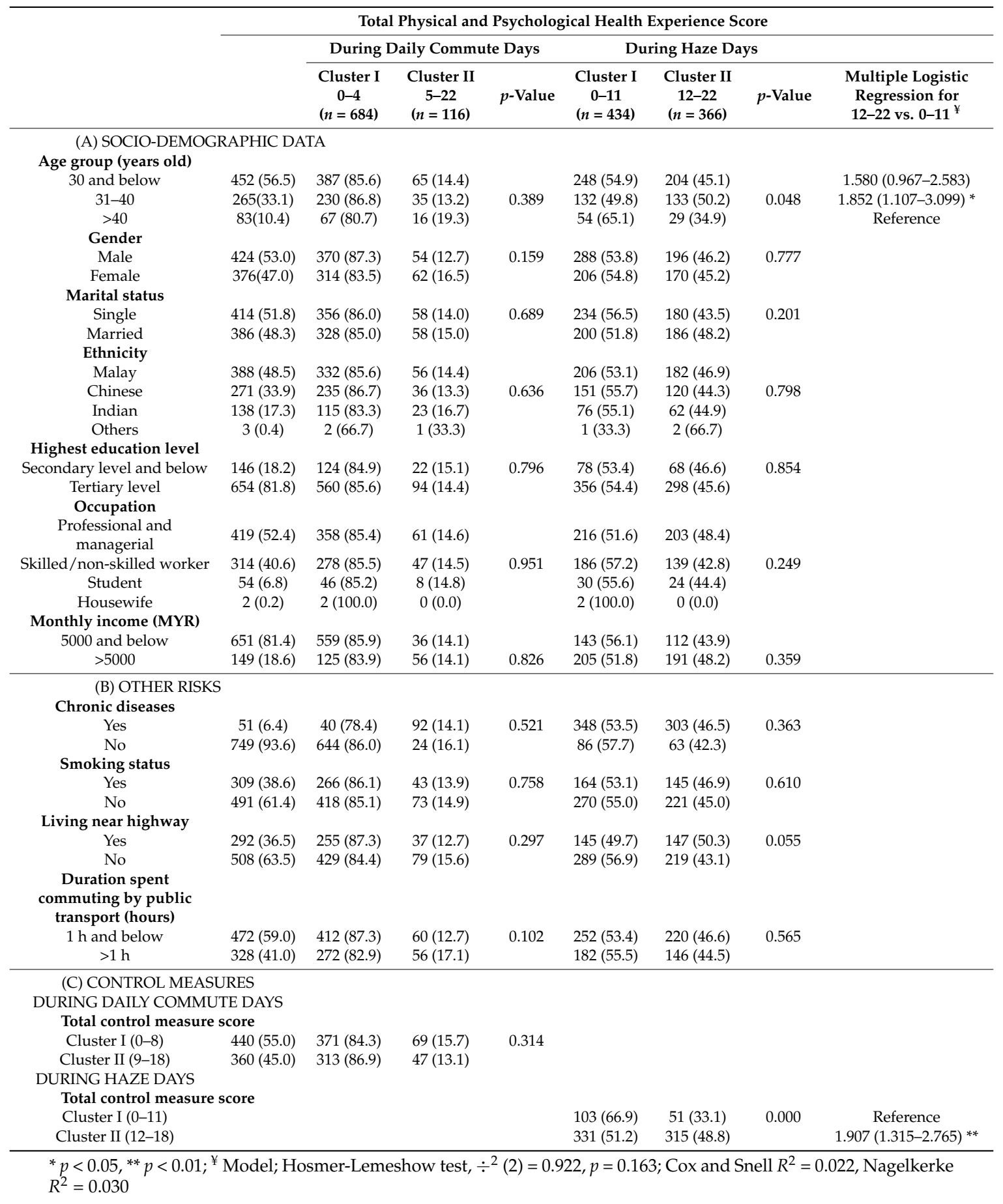

\section{Discussion}

Previous studies have found that the ambient air quality in the city of Kuala Lumpur, which is located close to the sites of our survey, is moderate, and there is evidence of illnesses related to air pollution associated with the duration of time spent in polluted areas [17]. Despite exposure to vehicular emissions during their daily commute, the vast majority of our study participants reported never/rarely practicing control measures to alleviate the adverse impact of air pollution during their daily commute. In particular, the use of respiratory protection was very low. Relatively higher 
proportions reported practicing health care measures such as drinking more water and increasing their consumption of fruits and vegetables rather than using respiratory protection. It has been highly recommended that public transport commuters use respiratory protection to reduce the health risks of exposure to particulate air pollution [18].

On a positive note, the employment of all control measures increased during haze days compared to normal commuting days. Higher increases were reported for the use of surgical masks, implying that, during haze days, using respiratory protection is most preferred by commuters. However, surgical masks have been reported as ineffective, as they will not prevent particles of 10 microns and less from entering the lungs. It is recommended that users employ appropriate masks, such as the N95 mask, which can filter out $95 \%$ of particulates larger than 0.3 microns [13]. This study found that during haze days, the use of N95 dust masks was not favored by our study participants. Although further investigation is warranted to explore the reason for the non-popularity of using N95 masks during haze days, this finding suggests that public transport commuters should be encouraged to use better filtering respirators such as N95 masks.

Smoking status was found to be significantly associated with total control measures against pollution during the normal daily commute. This finding suggests that cigarette smokers should be encouraged to enhance their control measures during the daily commute, as they are exposed to harmful chemicals from cigarette smoke in addition to air pollutants. In regard to total control measures during haze days, married participants were more likely to report higher usage of total control measures. This finding was in agreement with previous studies on health and mortality by marital status, which have consistently identified that unmarried individuals generally report less healthy behaviors and have a higher mortality risk than their married counterparts [19-21]. Younger age has been inversely associated with better health-related behavior [22,23]. Likewise, in this study, there was a nearly significant association between total control measures during haze days and age. This finding suggests the importance of encouraging younger commuters to also engage in control measures against exposure to air pollutants. They should be encouraged to start taking preventive measures at a young age, as there is longstanding evidence that has shown long-term exposure to air pollution to be associated with increased risk of cardiovascular, respiratory, and lung-cancer mortality [24-28]. Further, a lower proportion of participants who live near a highway, compared to those not living near a highway, reported high usage of total control measures, although a near significant association was found. This suggests the need to inform the public that there is substantial evidence of the link between exposure of near-highway residents to pollutants and adverse health outcomes [29]; thus, commuters living near a highway have prolonged exposure and should reduce exposure to air pollutants as much as possible during their commute.

The symptoms reported in this study during daily commuting, such as feelings of fatigue, dizziness, and respiratory effects, is in agreement with findings of other studies on health effects related to air quality and commuters' exposure to air pollution in traffic [30,31]. Further, the increased proportion of adverse physical and psychological health experiences during haze days, compared to normal commuting days, implies that the occurrence of haze added to the adverse health effects on commuters.

In this study, although reports of psychological health impacts were relatively lower compared to physical health effects for commuting during both normal and haze days, adverse psychological health should not be ignored. Psychological and emotional responses to air pollution can also be of significant importance because air pollution impacts lifespan and quality of life. The World Health Organization declares that health is "a state of complete physical, mental and social well-being and not merely the absence of disease or infirmity" [32]. It has been documented that the psychological effects of air pollution can lead to psychiatric symptoms, including anxiety disorders and changes in mood, cognition, and behavior, as well as to a reduction in psychological well-being [33-35]. Therefore, it is suggested that public transport commuters should learn to recognize the negative impact of air pollution on psychological health and seek appropriate and necessary treatment. 
In this study, the finding that older participants reported lower total health adverse experiences during haze days is unclear. Nonetheless, the fact that participants aged 31-40 were found to have a higher likelihood of total adverse health experiences during haze days than those younger than 30 could be due to longer duration of exposure to particulate air pollutants. As the exposure to air pollutants has been associated with longer time spent in the polluted area [14], this may imply that commuters aged 31-40 who may have been exposed for a longer duration than those who are younger and more vulnerable adverse health effects particularly during haze days where air pollutions heighten. As such, commuters who have been using public transport for a longer duration should be encouraged to take measures to reduce exposure to air pollutants. Further, the association between living near a highway and adverse health experiences, which almost reached statistical significance, may imply that multiple exposures to air pollution both at home and during the daily commute increase a person's risk for health problems. Thus, it is recommended that using air purifiers at home [36] or using houseplants as a way to purify the air in the home [37], in addition to proper respiratory protection, are steps that should be taken by those who live near highways in order to minimize exposure to air pollution and increase their health protection. Of note, this study did not find significant association between chronic illness and physical or psychological health experience. This perhaps due to small number of sample in this study reported having chronic conditions. Many studies have reported that effects of traffic-related pollution are more severe on people who are suffering from chronic obstructive pulmonary disease (COPD). A recent study reported that COPD-affected individuals received greater doses of UltraFine Particles (UFP) than healthy individual due to their higher respiratory rate [38]. Therefore avoiding exposure to air pollutants is important for individuals with COPD.

Since this was a cross-sectional study, we were unable to infer causality between control measures and adverse health experiences. The significant positive association between higher control measures and higher adverse health experiences during haze days could because participants who experienced higher adverse health effects were more aware or troubled by their adverse health experiences and thus carried out higher control measures in order to reduce the adverse health that they experienced. Further experimental studies that can empirically test causal relationships between control measures and adverse health experiences are warranted. It is suggested that commuters should also practice control measures regardless of whether or not they experience adverse health effects. Educational and motivational messages should be placed in public transport vehicles and terminals to encourage commuters to increase awareness about the hazards and to encourage the use of control measures against particulate air pollutants during their commute.

\section{Conclusions}

The findings from this study imply that there is a dire need to encourage commuters using public transportation in urban cities in Malaysia to use respiratory as well as other control measures to minimize exposure to particulate air pollutants during their daily commute, particularly during haze days. Evidence-based findings of the health hazards of air pollutants on commuters should be made known. Educational and motivational messages should be placed in public transport vehicles and terminals to encourage commuters to increase awareness about the hazards and to encourage the use of control measures against particulate air pollutants during their commute. The study findings provide important insights of urban planning solution for improving air quality as well as enhancing the sustainability of cities for growing urban populations.

\section{Limitation}

This study also has some limitations that warrant discussion. First, the results underscore the potential limitations of self-report responses. Social desirability bias can be an issue with self-reported data. Self-reporting can also cause recall bias. The second limitation concerns the convenience sampling used in this study, in that the sample may not be representative of all public transport commuters in all urban cities in Malaysia. 
Acknowledgments: The study was funded by Grand Challenge-SUS (Sustainability Science) Grants GC002C-15SUS and GC002A-15SUS.

Author Contributions: W.L.P., N.A. and N.M.N.S. conceived the study. W.L.P. and A.G. wrote the manuscript. A.G., W.L.P. and H.A. performed the data collection and data analysis. All authors read and approved the final manuscript.

Conflicts of Interest: The authors declare no conflict of interest. The founding sponsors had no role in the design of the study; in the collection, analyses, or interpretation of data; in the writing of the manuscript, and in the decision to publish the result.

\section{References}

1. Hoek, G.; Brunekreef, B.; Goldbohm, S.; Fischer, P.; van den Brandt, P.A. Association between mortality and indicators of traffic-related air pollution in the Netherlands: A cohort study. Lancet 2002, 360, 1203-1209. [CrossRef]

2. Adar, S.D.; Davey, M.; Sullivan, J.R.; Compher, M.; Szpiro, A.; Liu, L.J. Predicting airborne particle levels aboard Washington State school buses. Atmos. Environ. 2008, 42, 7590-7599. [CrossRef] [PubMed]

3. McCreanor, J.; Cullinan, P.; Nieuwenhuijsen, M.J.; Stewart-Evans, J.; Malliarou, E.; Jarup, L.; Harrington, R.; Svartengren, M.; Han, I.K.; Ohman-Strickland, P.; et al. Respiratory effects of exposure to diesel traffic in persons with asthma. N. Engl. J. Med. 2007, 357, 2348-2358. [CrossRef] [PubMed]

4. Peters, A.; Von Klot, S.; Heier, M.; Trentinaglia, I.; Hörmann, A.; Wichmann, H.E.; Löwel, H. Exposure to traffic and the onset of myocardial infarction. N. Engl. J. Med. 2004, 351, 1721-1730. [CrossRef] [PubMed]

5. Riediker, M.; Cascio, W.E.; Griggs, T.R.; Herbst, M.C.; Bromberg, P.A.; Neas, L.; Williams, R.W.; Devlin, R.B. Particulate matter exposure in cars is associated with cardiovascular effects in healthy young men. Am. J. Respir. Crit. Care Med. 2004, 169, 934-940. [CrossRef] [PubMed]

6. Strak, M.; Boogaard, H.; Meliefste, K.; Oldenwening, M.; Zuurbier, M.; Brunekreef, B.; Hoek, G. Respiratory health effects of ultrafine and fine particle exposure in cyclists. Occup. Environ. 2010, 67, 118-124. [CrossRef] [PubMed]

7. Shima, M.; Nitta, Y.; Adachi, M. Traffic-related air pollution and respiratory symptoms in children living along trunk roads in Chiba Prefecture, Japan. J. Epidemiol. 2003, 13, 108-119. [CrossRef] [PubMed]

8. Brauer, M.; Hoek, G.; Van Vliet, P.; Meliefste, K.; Fischer, P.H.; Wijga, A.; Koopman, L.P.; Neijens, H.J.; Gerritsen, J.; Kerkhof, M.; et al. Air pollution from traffic and the development of respiratory infections and asthmatic and allergic symptoms in children. Am. J. Respir. Crit. Care Med. 2002, 166, 1092-1098. [CrossRef] [PubMed]

9. Emmanuel, S.C. Impact to lung health of haze from forest fires: The Singapore experience. Respirology 2000, 5, 175-182. [CrossRef] [PubMed]

10. Forouzanfar, M.H.; Alexander, L.; Anderson, H.R.; Bachman, V.F.; Biryukov, S.; Brauer, M.; Burnett, R.; Casey, D.; Coates, M.M.; Cohen, A.; et al. Global, regional, and national comparative risk assessment of 79 behavioural, environmental and occupational, and metabolic risks or clusters of risks in 188 countries, 1990-2013: A systematic analysis for the Global Burden of Disease Study 2013. Lancet 2015, 386, 2287-2323. [CrossRef]

11. Langrish, J.P.; Li, X.; Wang, S.; Lee, M.M.; Barnes, G.D.; Miller, M.R.; Cassee, F.R.; Boon, N.A.; Donaldson, K.; $\mathrm{Li}$, J.; et al. Reducing personal exposure to particulate air pollution improves cardiovascular health in patients with coronary heart disease. Environ. Health Perspect. 2012, 120, 367. [CrossRef] [PubMed]

12. Cai, D.P.; He, Y.M. Daily lifestyles in the fog and haze weather. J. Thorac. Dis. 2016, 8, E75-E77. [PubMed]

13. Ren, J.; Li, B.; Yu, D.; Liu, J.; Ma, Z. Approaches to prevent the patients with chronic airway diseases from exacerbation in the haze weather. J. Thorac. Dis. 2016, 8, E1-E7. [PubMed]

14. Leh, O.L.; Ahmad, S.; Aiyub, K.; Jani, Y.M.; Hwa, T.K. Urban air environmental health indicators for Kuala Lumpur city. Sains. Malays. 2012, 41, 179-191.

15. Hartigan, J.A.; Wong, M.A. Algorithm AS 136: A k-means clustering algorithm. J. R. Stat. Soc. Ser. C (Appl. Stat.) 1979, 28, 100-108. [CrossRef]

16. Hosmer, D.W., Jr.; Lemeshow, S.; Sturdivant, R.X. Applied Logistic Regression; John Wiley \& Sons: New York, NY, USA, 2013.

17. Lobo, V.; Patil, A.; Phatak, A.; Chandra, N. Free radicals, antioxidants and functional foods: Impact on human health. Pharmacogn. Rev. 2010, 4, 118. [CrossRef] [PubMed] 
18. Laumbach, R.; Meng, Q.; Kipen, H. What can individuals do to reduce personal health risks from air pollution? J. Thorac. Dis. 2015, 7, 96-107. [PubMed]

19. Ben-Shlomo, Y.; Smith, G.D.; Shipley, M.; Marmot, M.G. Magnitude and causes of mortality differences between married and unmarried men. J. Epidemiol. Comm. Health 1993, 47, 200-205. [CrossRef]

20. Waldron, I.; Hughes, M.E.; Brooks, T.L. Marriage protection and marriage selection-Prospective evidence for reciprocal effects of marital status and health. Soc. Sci. Med. 1996, 43, 113-123. [CrossRef]

21. Robards, J.; Evandrou, M.; Falkingham, J.; Vlachantoni, A. Marital status, health and mortality. Maturitas 2012, 73, 295-299. [CrossRef] [PubMed]

22. Deeks, A.; Lombard, C.; Michelmore, J.; Teede, H. The effects of gender and age on health related behaviors. BMC Public Health. 2009, 9, 213. [CrossRef] [PubMed]

23. Davidson, D.J.; Freudenburg, W.R. Gender and environmental risk concerns: A review and analysis of available research. Environ. Behav. 1996, 28, 302-339. [CrossRef]

24. Crouse, D.L.; Peters, P.A.; van Donkelaar, A.; Goldberg, M.S.; Villeneuve, P.J.; Brion, O.; Khan, S.; Atari, D.O.; Jerrett, M.; Pope, C.A., III; et al. Risk of nonaccidental and cardiovascular mortality in relation to long-term exposure to low concentrations of fine particulate matter: A Canadian national-level cohort study. Environ. Health Perspect. 2012, 120, 708. [CrossRef] [PubMed]

25. Gan, W.; Koehoorn, M.; Davies, H.; Demers, P.; Tamburic, L.; Brauer, M. Long-term exposure to traffic-related air pollution and the risk of coronary heart disease hospitalization and mortality. Epidemiology 2011, 22, S30. [CrossRef]

26. Lepeule, J.; Laden, F.; Dockery, D.; Schwartz, J. Chronic exposure to fine particles and mortality: An extended follow-up of the Harvard Six Cities study from 1974 to 2009. Environ. Health Perspect. 2012, 120, 965. [CrossRef] [PubMed]

27. Lipsett, M.J.; Ostro, B.D.; Reynolds, P.; Goldberg, D.; Hertz, A.; Jerrett, M.; Smith, D.F.; Garcia, C.; Chang, E.T.; Bernstein, L. Long-term exposure to air pollution and cardiorespiratory disease in the California teachers study cohort. Am. J. Respir. Crit. Care Med. 2011, 184, 828-835. [CrossRef] [PubMed]

28. Cesaroni, G.; Badaloni, C.; Gariazzo, C.; Stafoggia, M.; Sozzi, R.; Davoli, M.; Forastiere, F. Long-term exposure to urban air pollution and mortality in a cohort of more than a million adults in Rome. Environ. Health Perspect. (Online) 2013, 121, 324. [CrossRef] [PubMed]

29. Brugge, D.; Durant, J.L.; Rioux, C. Near-highway pollutants in motor vehicle exhaust: A review of epidemiologic evidence of cardiac and pulmonary health risks. Environ. Health 2007, 6, 23. [CrossRef] [PubMed]

30. Lercher, P.; Schmitzberger, R.; Kofler, W. Perceived traffic air pollution, associated behavior and health in an alpine area. Sci. Total Environ. 1995, 169, 71-74. [CrossRef]

31. Zuurbier, M.; Hoek, G.; Oldenwening, M.; Meliefste, K.; van den Hazel, P.; Brunekreef, B. Respiratory effects of commuters' exposure to air pollution in traffic. Epidemiology 2011, 22, 219-227. [CrossRef] [PubMed]

32. World Health Organization. Promoting Mental Health: Concepts, Emerging Evidence, Practice: Summary Report; World Health Organization: Geneva, Switzerland, 2004.

33. Lundberg, A. Psychiatric aspects of air pollution. Otolaryngol. Head Neck Surg. 1996, 114, 227-231. [CrossRef]

34. Genc, S.; Zadeoglulari, Z.; Fuss, S.H.; Genc, K. The adverse effects of air pollution on the nervous system. J. Toxicol. 2012. [CrossRef] [PubMed]

35. Power, M.C.; Kioumourtzoglou, M.A.; Hart, J.E.; Okereke, O.I.; Laden, F.; Weisskopf, M.G. The relation between past exposure to fine particulate air pollution and prevalent anxiety: observational cohort study. BMJ 2015, 350, h1111. [CrossRef] [PubMed]

36. Vijayan, V.K.; Paramesh, H.; Salvi, S.S.; Dalal, A.A. Enhancing indoor air quality-The air filter advantage. Lung India 2015, 32, 473. [CrossRef] [PubMed]

37. Claudio, L. Planting healthier indoor air. Environ. Health Perspect. 2011, 119, a426-427. [CrossRef] [PubMed]

38. Manigrasso, M.; Natale, C.; Vitali, M.; Protano, C.; Avino, P. Pedestrians in Traffic Environments: Ultrafine Particle Respiratory Doses. Int. J. Environ. Res. Public Health. 2017, 14, E288. [CrossRef] [PubMed]

(C) 2017 by the authors. Licensee MDPI, Basel, Switzerland. This article is an open access article distributed under the terms and conditions of the Creative Commons Attribution (CC BY) license (http:/ / creativecommons.org/licenses/by/4.0/). 